\title{
Wideband Printed Monopole Antenna for Application in Wireless Communication Systems
}

\author{
Mohammad Alibakhshikenari ${ }^{1 *}$, Bal S. Virdee ${ }^{2}$, Abdul Ali $^{1}$, and Ernesto Limiti ${ }^{1}$ \\ ${ }^{1}$ Electronics Engineering Department, University of Rome "Tor Vergata", Via del Politecnico 1, 00133 Rome - \\ ITALY \\ ${ }^{2}$ London Metropolitan University, Center for Communications Technology, School of Computing \& Digital Media, \\ London N7 8DB, UK \\ alibakhshikenari@ing.uniroma2.it*
}

\begin{abstract}
Empirical results of an electrically small printed monopole antenna is described with fractional bandwidth of $185 \%(115 \mathrm{MHz}-2.90 \mathrm{GHz})$ for return-loss better than $10 \mathrm{~dB}$, peak gain and radiation efficiency at $1.45 \mathrm{GHz}$ of $2.35 \mathrm{dBi}$ and $78.8 \%$, respectively. The antenna geometry can be approximated to a back-to-back triangular shaped patch structure that is excited through a common feed-line with a meander-line T-shape divider. The truncated ground-plane includes a central stub located underneath the feed-line. The impedance bandwidth of the antenna is enhanced with the inclusion of meander-line slots in the patch and four double split-ring resonators on the underside of the radiating patches. The antenna radiates approximately omnidirectionally to provide coverage over a large part of VHF, whole of UHF, entire of L-band and some parts of S-band. The antenna has dimensions of $48.32 \times 43.72 \times 0.8 \mathrm{~mm}^{3}$, which is corresponding with the electrical size of $0.235 \lambda_{0} \times 0.211 \lambda_{0} \times 0.003 \lambda_{0}$, where $\lambda_{0}$ is free-space wavelength at $1.45 \mathrm{GHz}$. The proposed lowprofile low-cost antenna is suitable for application in wideband wireless communications systems.
\end{abstract}

Keywords - Printed monopole antenna, wideband antenna, truncated ground plane, back-to-back triangular shaped radiation patch, split ring resonators (SRR).

\section{INTRODUCTION}

Advanced modern wireless systems incorporate various radio frequency technologies such as WiFi, WiMAX, Zigbee, $3 \mathrm{G}$ and LTE. The antennas for these systems therefore need to satisfy stringent requirements including wide impedance bandwidth, omnidirectional radiation, stable gain and radiation pattern, and low profile design [1]-[6]. In the past decades, tremendous research has been carried out to achieve various design objectives. Several wideband low profile antennas have been designed by employing slot antenna [7]-[10], loop antenna [11], [12] and spiral antenna [13]-[15]. Electromagnetic band-gap (EBG) structure, which is an artificial electromagnetic material, has been used to reduce the antenna dimensions to less than $0.1 \lambda_{0}$. This has been demonstrated by locating a dipole antenna [16] or a folded dipole antenna [17] or a spiral antenna [18] on a carefully designed EBG structure. Essentially, the operating bandwidth of the antenna is limited by the bandwidth of the reflection phase of the EBG surface; hence wideband antennas cannot be excited on the EBG surface.

Microstrip patch antenna is an alternative solution to achieve a low-profile design, which has many advantages, such as planar structure, low cost, and ease of manufacture. However, conventional patch antennas [19] suffer from very narrow impedance bandwidth (less than 5\%), which therefore cannot fulfill the bandwidth requirement of the modern wireless system. Numerous bandwidth enhancement techniques have been reported to date, such as the L-probe feed [20], [21], coplanar coupled feed [22], aperture coupled feed [23], stacked patches [24], U-slot patch [25] and E-shaped patch [26]. With these techniques the impedance bandwidth has been greatly enhanced by up to $50 \%$ for $\mathrm{VSWR} \leq 2$. However, the radiation patterns of these patch antennas vary with frequency, and they can suffer from high crosspolarization and strong back radiation across their operating frequency range.

In this paper, a novel wideband printed monopole antenna structure is reported. The antenna is composed 
of back-to-back triangular shaped radiating patches that are excited through a common feed-line. The groundplane of the antenna is a truncated T-shaped structure that is located under the feed-line. Etched in the patches is a meandered slot line, and embedded under the two patches are four double split-ring resonators. These elements stretch regions of well-matched impedance and therefore enhance the antenna's impedance bandwidth. The proposed antenna radiates approximately omnidirectionally over $115 \mathrm{MHz}-2.90 \mathrm{GHz}$. The antenna is compact with dimensions of $0.235 \lambda_{0} \times 0.211 \lambda_{0} \times 0.003 \lambda_{0}$ at $1.45 \mathrm{GHz}$ that enables easy integrated with RF font-end circuitry.

\section{ANTENNA DESIGN}

Geometry of the proposed antenna, shown in Fig. 1(a), is constituted from two identical back-to-back printed patches that be approximated to a triangular shape or can be considered to resemble a tree like structure. The treeshaped patches are placed in close proximity to each other and fed through a common feed-line through a Tshape divider. On the bottom side of the antenna substrate is a truncated ground-plane, shown in Fig. 1(b).

The antenna structure was simulated using High Frequency Structure Simulator (HFSS), which is a full wave electromagnetic simulator. From the simulation response of Antenna\#1, shown in Fig. 2, it is discernible that the antenna exhibits two visible notched-bands. The bandwidth and gain of Antenna\#1 are given in Table 1. To eliminate these notched bands, the T-junction of the feed-line connecting the tree-shaped patches is meandered and a ground-plane stub is added on the bottom side of the substrate. The ground-plane, shown in Fig. 1(c), now resembles a T-shape structure where the ground stub is located underneath the feed-line. Careful design of the meandered line (ML) T-shaped junction and ground-plane stub eliminate the notched bands, which is evident in Fig. 2.

The antenna was constructed on Rogers/RT Duroid 5880 substrate with dielectric constant of 2.2, thickness of $0.8 \mathrm{~mm}$, and loss-tangent of 0.0009 . The ML and ground stub also improve the impedance matching from $S_{11} \leq-18 \mathrm{~dB}$ to $-20 \mathrm{~dB}$, however the resonance frequency is shifted from $1.47 \mathrm{GHz}$ to $1.40 \mathrm{GHz}$ with $28 \%$ reduction in the impedance bandwidth. Fig. 3 shows the measured gain and efficiency performance of Antenna\#1, and the salient results are given in Table 2. Maximum gain and efficiency at the resonance frequency of $f_{r}=1.55 \mathrm{GHz}$ are $0.35 \mathrm{dBi}$ and $22.8 \%$, respectively. Table 3 compares simulated and measured impedance bandwidth, resonant frequency and returnloss. The discrepancies in the result are attributed to manufacturing tolerance and imperfect soldering of the SMA connector to the antenna feed-line.

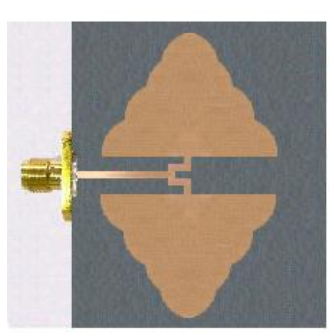

(a)

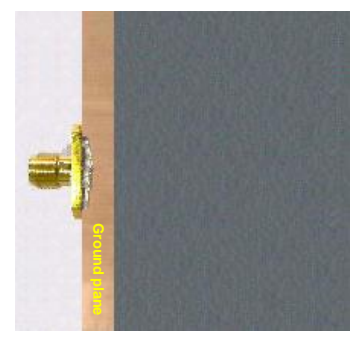

(b)

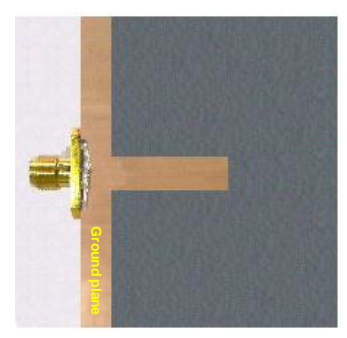

(c)

Fig. 1. Photograph of the proposed Antenna\#1, a) top side, b) bottom side, and c) modified ground-plane. (Dimensions given in Table 4). 


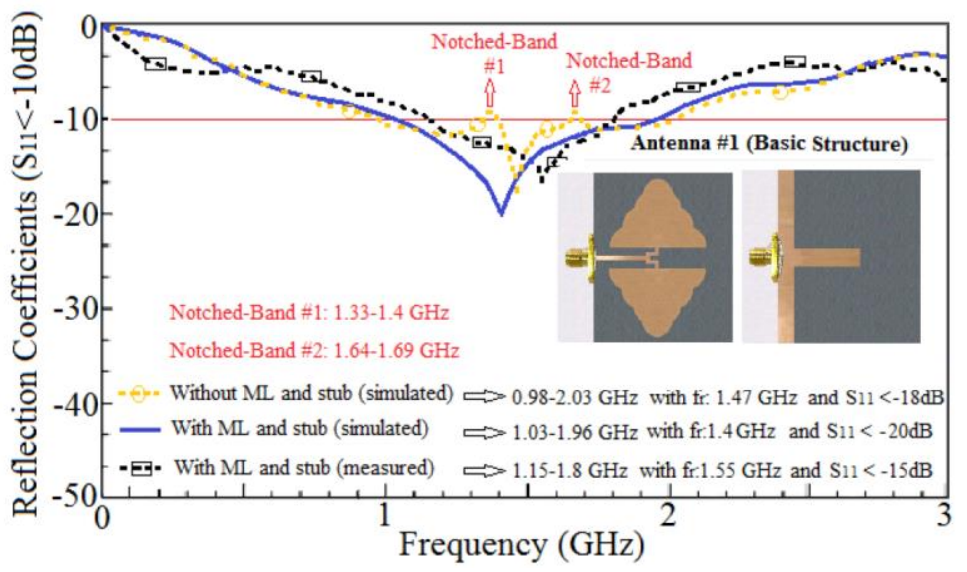

Fig. 2. Reflection coefficient response of Antenna\#1. (Dimensions are given in Table 4).

Table 1. Bandwidth and gain of the band notches in Antenna\#1

\begin{tabular}{|l|c|}
\hline Band notch \#1 & $1.33-1.4 \mathrm{GHz} \rightarrow-0.14 \leq$ Gain $\leq-0.05$ \\
\hline Band notch \#2 & $1.64-1.69 \mathrm{GHz} \rightarrow-0.82 \leq$ Gain $\leq-0.03$ \\
\hline
\end{tabular}

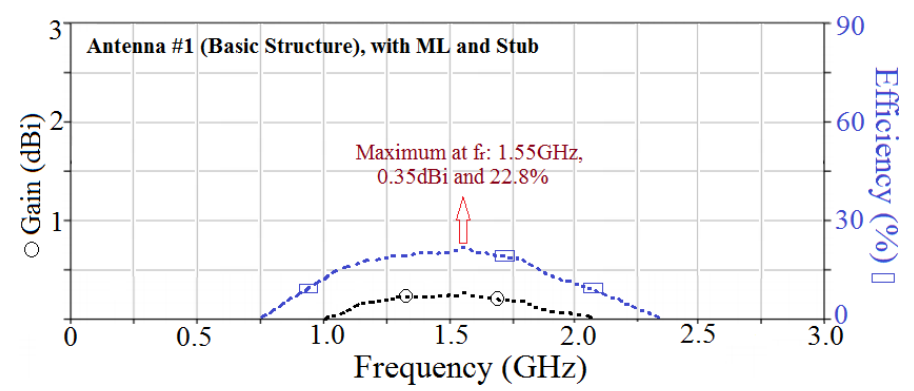

Fig. 3. Measured gain and efficiency response as a function of frequency of Antenna\#1 (basic structure) with meandered line T-junction feed and ground-plane stub.

Table 2. Measured gain and efficiency performance of Antenna\#1 with ML and ground stub

\begin{tabular}{|c|c|c|c|}
\hline Frequency $(\mathrm{GHz})$ & 1.15 & $f_{r}=1.55$ & 1.8 \\
\hline Gain $(\mathrm{dBi})$ & 0.2 & 0.35 & 0.27 \\
\hline Efficiency $(\%)$ & 17.35 & 22.8 & 19.58 \\
\hline
\end{tabular}

Table 3. Simulated and measured impedance bandwidth, resonant frequency and return-loss of Antenna\#1

\begin{tabular}{|c|}
\hline Simulated freq. range (Fractional $B W$ ): $1.03-1.96 \mathrm{GHz}(62.20 \%), f_{r_{\text {sim. }}}=1.4 \mathrm{GHz}$ and $S_{11_{\text {sim. }}}$ better than $20 \mathrm{~dB}$ \\
\hline Measured freq. range (Fractional $B W$ ): $1.15-1.8 \mathrm{GHz}(44.06 \%), f_{r_{\text {meas. }}}=1.55 \mathrm{GHz}$ and $S_{11_{\text {meas. }}}$ better than $15 \mathrm{~dB}$ \\
\hline
\end{tabular}

\section{ENHANCING RADIATION CHARACTERISTICS}

To improve the radiation characteristics of Antenna\#1 a meandered line slot was etched on both the tree-shaped patches, as shown in Fig. 4. The dimensions of the antenna parameters are given in Table 4. Dimensions of the two-identical back-to-back printed patches are based on an approximation for a triangular microstrip antenna whose resonant frequencies were obtained from cavity model with perfect magnetic walls given by [27]:

$$
f_{m n}=\frac{2 c}{3 a \sqrt{\left(\varepsilon_{r}\right)}}\left[m^{2}+m n+n^{2}\right]^{1 / 2}
$$

where $\mathrm{c}$ is the velocity of electromagnetic waves in free space, $\varepsilon_{r}$ is the relative dielectric constant of the substrate, $m$ and $n$ are the integers which refer to TM 
modes, and $a$ is the length of a side of the triangle. The reflection coefficient response of Antenna\#2 in Fig. 5 shows improvement in the impedance bandwidth. Two new regions of well matched impedance are produced by the additional slots at $f_{r l}=1.33 \mathrm{GHz}$ and $f_{r 3}=1.75 \mathrm{GHz}$.

The radiation pattern of the antenna was measured in a compact range anechoic chamber with a horn antenna transmitting spherical waves towards a reflector that converted the incident waves to plane waves which were directed towards the proposed antenna under test. Fig. 6 show that Antenna\#2 has a maximum gain and radiation efficiency of $2 \mathrm{dBi}$ and $70 \%$, respectively, at $f_{r 3}=1.75 \mathrm{GHz}$. Other details are given in Table 5. This improvement is approximately four-fold that of Antenna\#1. Table 6 compares simulated and measured impedance bandwidth, resonant frequency and return-loss. The discrepancies in the result are attributed to manufacturing tolerance and imperfect soldering of the SMA connector to the antenna feed-line.

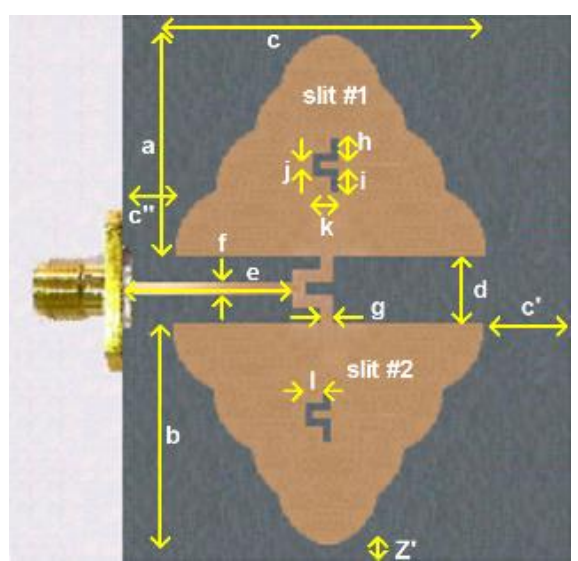

(a)

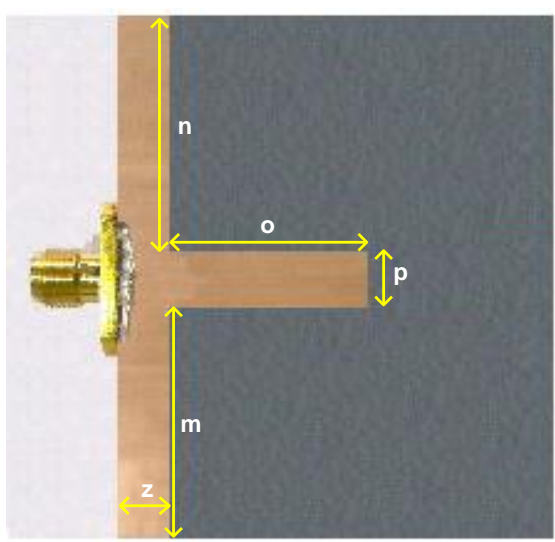

(b)

Fig. 4. Antenna\#2 is essentially Antenna\#1 with a meandered line etched on both patches, a) front view, b) back view.

Table 4. Antenna parameter values in millimeters. Antenna size is: $48.32 \times 43.72 \times 0.8 \mathrm{~mm}^{3}$ on Rogers/RT Duroid 5880

\begin{tabular}{|c|c|c|c|c|c|c|c|c|c|}
\hline $\mathrm{a}$ & $\mathrm{b}$ & $\mathrm{c}$ & $\mathrm{d}$ & $\mathrm{e}$ & $\mathrm{f}$ & $\mathrm{g}$ & $\mathrm{h}$ & $\mathrm{i}$ & $\mathrm{j}$ \\
\hline 19.48 & 19.48 & 31 & 6.36 & 16 & 1.4 & 1.5 & 2 & 2 & 2 \\
\hline
\end{tabular}

\begin{tabular}{|c|c|c|c|c|c|c|c|c|c|}
\hline $\mathrm{k}$ & $\mathrm{l}$ & $\mathrm{m}$ & $\mathrm{n}$ & $\mathrm{o}$ & $\mathrm{p}$ & $\mathrm{z}$ & $z^{\prime}$ & $c^{\prime}$ & $c^{\prime \prime}$ \\
\hline 2.4 & 1.6 & 24 & 24 & 20 & 6 & 5.2 & 1.5 & 7.86 & 4.86 \\
\hline
\end{tabular}

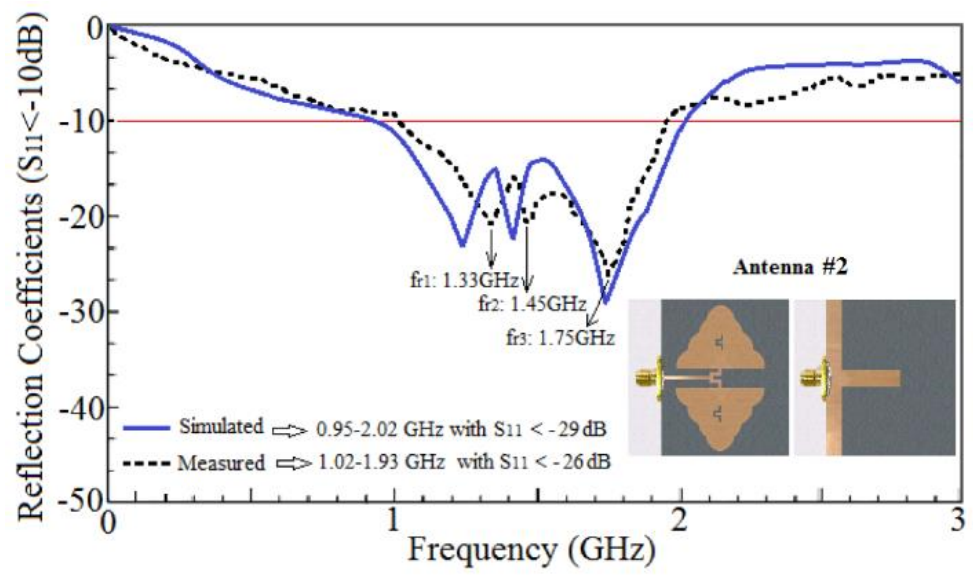

Fig. 5. Reflection coefficient response for Antenna\#2. 


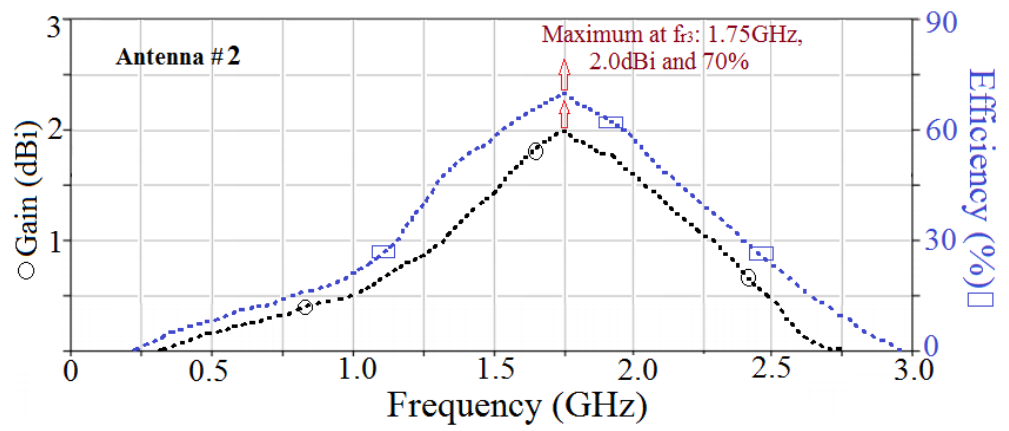

Fig. 6. Measured gain and efficiency response as a function of frequency for Antenna\#2.

Table 5. Measured gain and efficiency performance of Antenna\#2

\begin{tabular}{|c|c|c|c|c|c|}
\hline Frequency $(\mathrm{GHz})$ & 1.02 & $f_{r 1}=1.33($ slot \#2) & $f_{r 2}=1.45(\mathrm{ML}$ and ground stub) & $f_{r 3}=1.75(\mathrm{slot} \# 1)$ & 1.93 \\
\hline Gain $(\mathrm{dBi})$ & 0.55 & 1.05 & 1.37 & 2.00 & 1.75 \\
\hline Efficiency $(\%)$ & 22.82 & 47.11 & 56.26 & 70.00 & 62.48 \\
\hline
\end{tabular}

Table 6. Simulated and measured impedance bandwidth, resonant frequency and return-loss of Antenna\#2

\begin{tabular}{|c|c|}
\hline Bandwidth and Fractional $B W \%$ & Simulated: $1.07 \mathrm{GHz}$ from $0.95-2.02 \mathrm{GHz}, 72.05 \%$ \\
\cline { 2 - 2 } & Measured: $0.91 \mathrm{GHz}$ from $1.02-1.93 \mathrm{GHz}, 61.69 \%$ \\
\hline \multirow{2}{*}{ First resonance frequency } & Simulated: $1.24 \mathrm{GHz}$ for $\left|\mathrm{S}_{11}\right| \leqq 23 \mathrm{~dB}$ \\
\cline { 2 - 2 } & Measured: $1.33 \mathrm{GHz}$ for $\left|\mathrm{S}_{11}\right| \leqq 20 \mathrm{~dB}$ \\
\hline \multirow{2}{*}{ Second resonance frequency } & Simulated: $1.42 \mathrm{GHz}$ for $\left|\mathrm{S}_{11}\right| \leqq 23 \mathrm{~dB}$ \\
\cline { 2 - 2 } & Measured: $1.45 \mathrm{GHz}$ for $\left|\mathrm{S}_{11}\right| \leqq 20 \mathrm{~dB}$ \\
\hline Third resonance frequency & Simulated: $1.74 \mathrm{GHz}$ for $\left|\mathrm{S}_{11}\right| \leqq 29 \mathrm{~dB}$ \\
\cline { 2 - 2 } & Measured: $1.75 \mathrm{GHz}$ for $\left|\mathrm{S}_{11}\right| \leqq 26 \mathrm{~dB}$ \\
\hline
\end{tabular}

\section{ENHANCING IMPEDANCE BANDWIDTH}

Besides having a good radiation characteristic, it is important the antenna has a wide impedance bandwidth and good matching performance to provide suitable coverage over several communications standards. This was achieved by loading the bottom side of the antenna substrate with split-ring resonators (SRR), as shown in Fig. 7. At the operating frequency the magnetic-flux penetrating the SSR induces rotating currents in the rings, which produce their own flux to enhance or oppose the incident field. Due to splits in the rings the structure can support resonant wavelengths much larger than the diameter of the rings. The small gaps between the rings creates a large capacitance that lowers the resonating frequency of the SRR. The dimensions of SRR are small compared to the resonant wavelength. The dimensions of
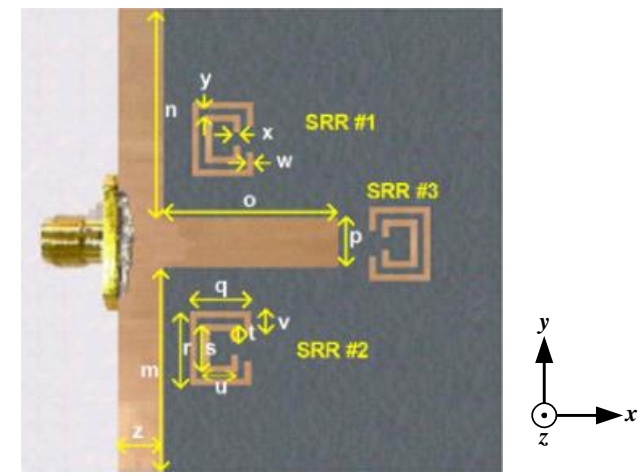

Fig. 7. Antenna\#3, which is based on Antenna\#1 includes three SRRs on the ground-plane. (Dimensions are given in Table 7).

Table 7. Split-ring resonator (SRR) parameter values in millimeters.

\begin{tabular}{|c|c|c|c|c|c|c|c|c|}
\hline $\mathrm{q}$ & $\mathrm{r}$ & $\mathrm{s}$ & $\mathrm{t}$ & $\mathrm{u}$ & $\mathrm{v}$ & $\mathrm{w}$ & $\mathrm{x}$ & $\mathrm{y}$ \\
\hline 7.2 & 8.7 & 5.7 & 1.98 & 4 & 2.8 & 0.8 & 0.8 & 0.8 \\
\hline
\end{tabular}


A parameter study was conducted to determine how the key parameters, i.e. ground stub, patch slit, and SRR, affected the performance of the antenna. Fig. 8(a) shows the effect of the ground stub length (o) and width (p) on the gain and radiation efficiency of the proposed antenna. It is clear from this graph that by increasing the length and width of the ground stub the antenna's effective aperture is increased, and the consequence of this is enhanced antenna gain and efficiency performance. When ground stub length and width are increased from $o=10 \mathrm{~mm}$ and $\mathrm{p}=2 \mathrm{~mm}$ to $o=20 \mathrm{~mm}$ and $\mathrm{p}=6 \mathrm{~mm}$, the gain and efficiency are increased by $1.1 \mathrm{dBi}$ and $32.9 \%$ at $1.45 \mathrm{GHz}$, respectively.

The effect of number of the SRRs on the radiation characteristics are shown in Figs. 8(b) \& (c). It is evident that by increasing the SRRs from one to three, the gain and efficiency correspondingly increase too. In fact, at $1.45 \mathrm{GHz}$ the gain and efficiency increase by $0.36 \mathrm{dBi}$ and $8.67 \%$, respectively.

Fig. 8(d) show the effect of the patch slot on the gain and efficiency of the antenna. When the length and width of the slot are increased from $2 \mathrm{~mm} \& 1 \mathrm{~mm}$ (initial case), respectively, to $6 \mathrm{~mm} \& 2 \mathrm{~mm}$ (optimized case), the antenna's gain and efficiency improve by $0.23 \mathrm{dBi}$ and $18.2 \%$, respectively. The bandwidth is also enhanced by $17.3 \%$. These results reveal the electromagnetic interaction between the patch and slot contribute in enhancing the antenna's performance. This is because a longer slot length effectively improves the impedance matching of the antenna. With this technique a smaller aperture is achieved with no compromise in the antenna's characteristics.

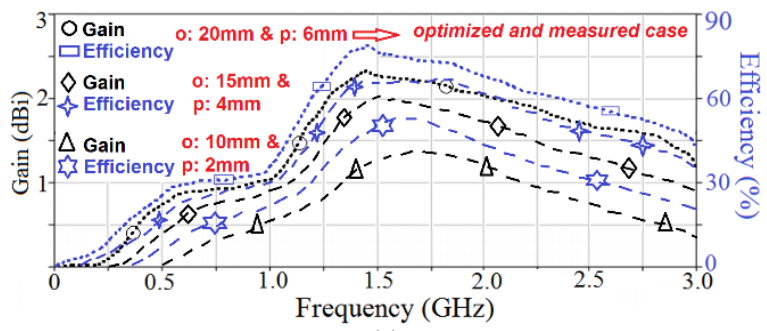

(a)

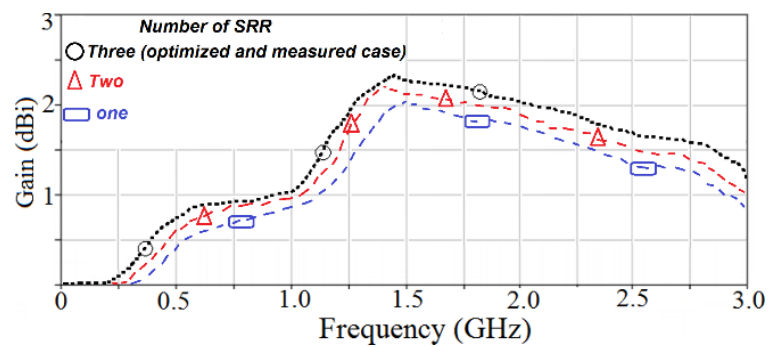

(b)

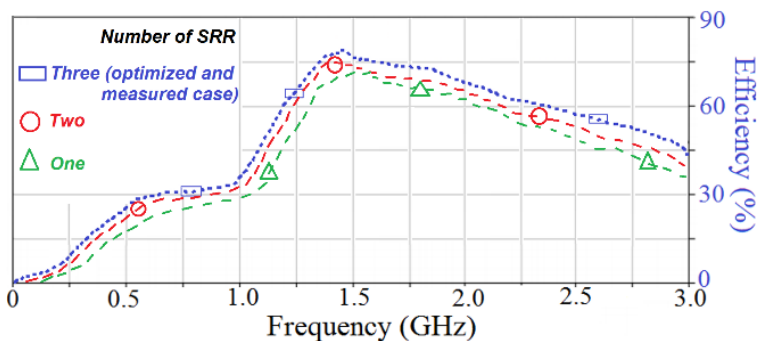

(c)

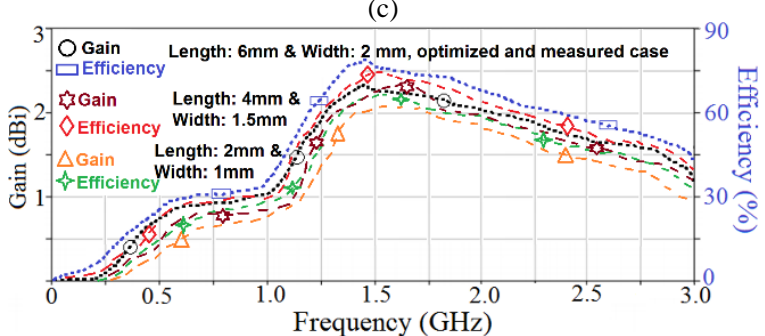

(d)

Fig. 8. Parametric study on the antenna's key parameters: a) length and width of the ground stub, b) number of SRRs on antenna gain, c) number of SRRs on antenna efficiency, and d) length and width of the patch slot.

Reflection coefficient, gain and efficiency responses of Antenna\#3 are shown in Figs. 9 and 10, and salient characteristics given in Table 8 . By loading three SRRs resulted in three new regions of well-matched impedance centered at $f_{r 4}=1.85 \mathrm{GHz}, f_{r 5}=2.15 \mathrm{GHz}$, and $f_{r 6}=2.5 \mathrm{GHz}$. SRRs extend the impedance bandwidth and improve the matching performance, however increase the radiation characteristics only moderately.

Current density distribution over the groundplane stub and split-ring resonators at various resonance frequencies, in Fig. 11, shows the current density is more pronounced at the mid-band frequency of $1.45 \mathrm{GHz}$. At this frequency $\left(f_{r 3}\right)$ the measured gain and efficiency of Antenna\#3 have an optimum value of $2.35 \mathrm{dBi}$ and $78.8 \%$, respectively.

Measured co- and cross-radiation patterns in Eand $\mathrm{H}$-planes at its operating frequencies are given in Figs. 12 and 13. At $f_{r 1}=0.55 \mathrm{GHz}, f_{r 2}=1.0 \mathrm{GHz}, f_{r 3}=$ $1.45 \mathrm{GHz}$, and $f_{r 6}=2.5 \mathrm{GHz}$, the cross-polarization radiation in E-plane is very low. Table 9 compares simulated and measured impedance bandwidth, resonant frequency and return-loss. Discrepancies in the result are attributed to manufacturing tolerance and imperfect soldering of the SMA connector to the antenna feed-line. The proposed antenna covers parts of VHF, whole of UHF, entire L-band and some parts of the S-band, as indicated in Table 10. 


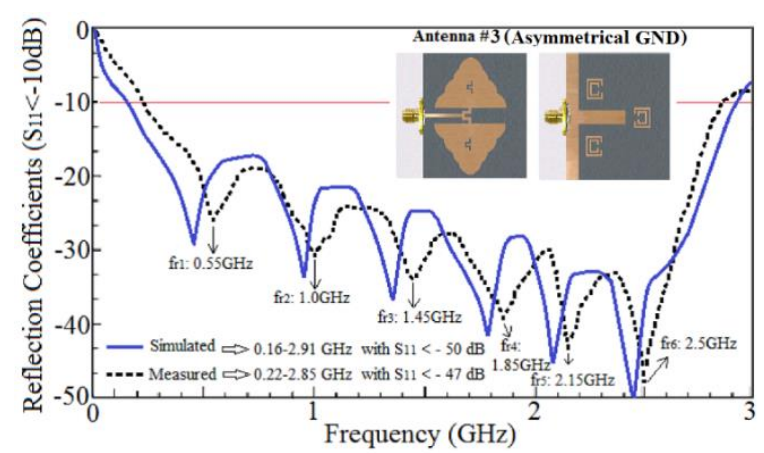

Fig. 9. Reflection coefficient response for Antenna\#3.

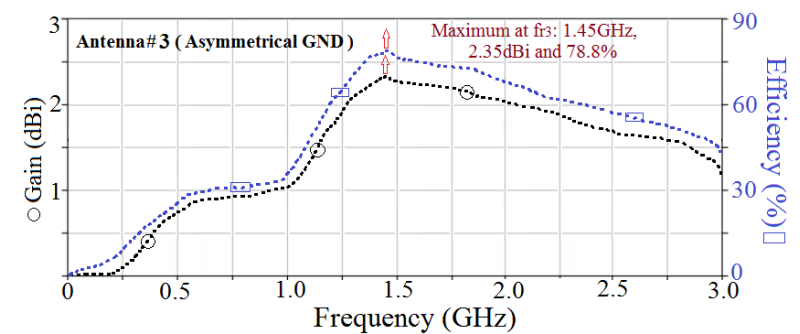

Fig. 10. Measured gain and efficiency as a function of frequency for Antenna\#3.

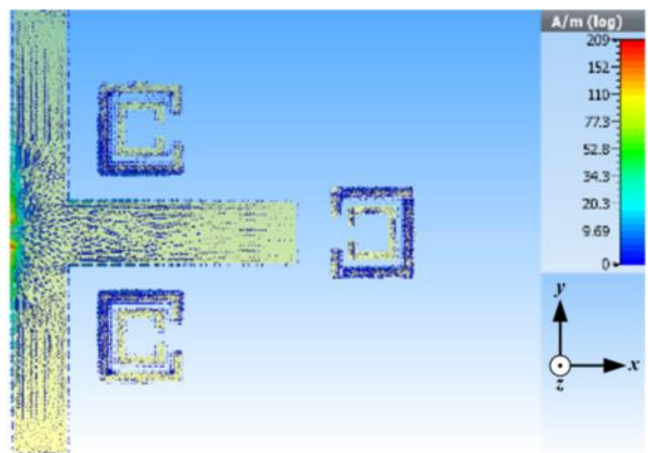

@ $f_{r l}=0.55 \mathrm{GHz}$

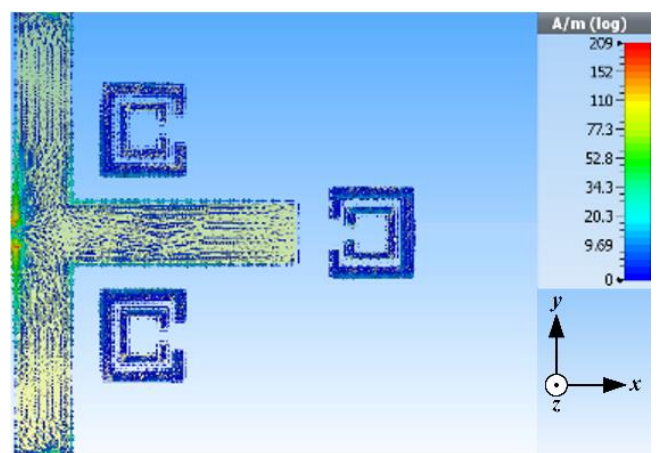

@ $f_{r 3}=1.45 \mathrm{GHz}$

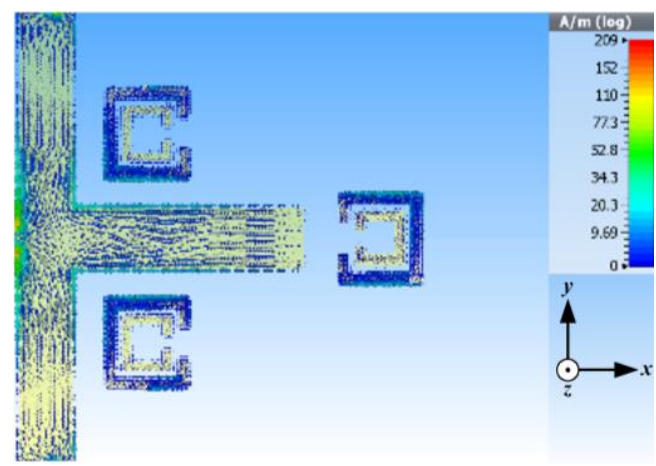

@ $f_{r 6}=2.5 \mathrm{GHz}$

Fig. 11. Surface current density distribution at spot frequencies.

Table 8. Measured gain and efficiency performance of Antenna\#3

\begin{tabular}{|l|c|c|c|c|c|c|c|c|}
\hline Freq.(GHz) & 0.22 & $\begin{array}{c}f_{r 1}=0.55 \\
\text { (slot\#2) }\end{array}$ & $\begin{array}{c}f_{r 2}=1 \\
\text { (ML \& stub) }\end{array}$ & $\begin{array}{c}f_{r 3}=1.45 \\
(\text { slot\#1) }\end{array}$ & $\begin{array}{c}f_{r 4}=1.85 \\
\text { (SRR\#1) }\end{array}$ & $\begin{array}{c}f_{r 5}=2.15 \\
\text { (SRR\#2) }\end{array}$ & $\begin{array}{c}f_{r 6}=2.5 \\
(\text { SRR\#3) }\end{array}$ & 2.85 \\
\hline Gain (dBi) & 0.05 & 0.85 & 1.04 & 2.35 & 2.18 & 1.95 & 1.72 & 1.52 \\
\hline Eff. (\%) & 7.44 & 28.57 & 36.1 & 78.85 & 72.53 & 64.39 & 57.65 & 50.3 \\
\hline
\end{tabular}


Table 9. Simulated and measured impedance bandwidth, resonant frequency and return-loss of Antenna\#3

\begin{tabular}{|c|c|}
\hline $\begin{array}{c}\text { Bandwidth, Freq. range \& } \\
\text { Fractional } B W \%\end{array}$ & Simulated: $2.75 \mathrm{GHz}, 0.16-2.91 \mathrm{GHz}, 179.15 \%$ \\
\cline { 2 - 2 } & Measured: $2.63 \mathrm{GHz}, 0.22-2.85 \mathrm{GHz}, 171.33 \%$ \\
\hline \multirow{2}{*}{ st $^{\text {resonance frequency }}$} & Simulated: $0.46 \mathrm{GHz}$ for $\left|\mathrm{S}_{11}\right| \leqq 28 \mathrm{~dB}$ \\
\cline { 2 - 2 } & Measured: $0.55 \mathrm{GHz}$ for $\left|\mathrm{S}_{11}\right| \leqq 25 \mathrm{~dB}$ \\
\hline \multirow{2}{*}{$2^{\text {nd }}$ resonance frequency } & Simulated: $0.96 \mathrm{GHz}$ for $\left|\mathrm{S}_{11}\right| \leqq 33 \mathrm{~dB}$ \\
\hline \multirow{2}{*}{$3^{\text {rd }}$ resonance frequency } & Measured: $1.0 \mathrm{GHz}$ for $\left|\mathrm{S}_{11}\right| \leqq 30 \mathrm{~dB}$ \\
\cline { 2 - 2 } & Simulated: $1.35 \mathrm{GHz}$ for $\left|\mathrm{S}_{11}\right| \leqq 35 \mathrm{~dB}$ \\
\hline \multirow{2}{*}{$4^{\text {th }}$ resonance frequency } & Measured: $1.45 \mathrm{GHz}$ for $\left|\mathrm{S}_{11}\right| \leqq 32 \mathrm{~dB}$ \\
\hline \multirow{2}{*}{$5^{\text {th }}$ resonance frequency } & Simulated: $1.79 \mathrm{GHz}$ for $\left|\mathrm{S}_{11}\right| \leqq 42 \mathrm{~dB}$ \\
\cline { 2 - 2 } & Measured: $1.85 \mathrm{GHz}$ for $\left|\mathrm{S}_{11}\right| \leqq 38 \mathrm{~dB}$ \\
\hline \multirow{2}{*}{$6^{\text {th }}$ resonance frequency } & Simulated: $2.08 \mathrm{GHz}$ for $\left|\mathrm{S}_{11}\right| \leqq 45 \mathrm{~dB}$ \\
\cline { 2 - 2 } & Seasured: $2.15 \mathrm{GHz}$ for $\left|\mathrm{S}_{11}\right| \leqq 44 \mathrm{~dB}$ \\
\cline { 2 - 2 } & Simulated: $2.45 \mathrm{GHz}$ for $\left|\mathrm{S}_{11}\right| \leqq 50 \mathrm{~dB}$ \\
\hline
\end{tabular}

Table 10. Wireless communication system frequencies covered by the proposed antenna.

\begin{tabular}{|c|c|}
\hline System & Operating Frequency \\
\hline Advanced Mobile Phone Service (AMPS) & $824-894 \mathrm{MHz}$ \\
\hline Lower Band of Global System for Mobile Communications (GSM) & $880-960 \mathrm{MHz}$ \\
\hline Personal Communication Service (PCS) & $1.71-1.88 \mathrm{GHz}$ \\
\hline Upper Band of Global System for Mobile Communications (GSM) & $1.85-1.99 \mathrm{GHz}$ \\
\hline Wideband Code Division Multiple Access (WCDMA) & $1.92-2.17 \mathrm{GHz}$ \\
\hline Universal Mobile Telecommunication Systems (UMTS) & $1.92-2.17 \mathrm{GHz}$ \\
\hline Personal Communication System (PCS) & $1.85-1.99 \mathrm{GHz}$ \\
\hline Cellular & $824-894 \mathrm{MHz}$ \\
\hline Digital Cellular System (DCS) & $1.71-1.88 \mathrm{GHz}$ \\
\hline GSM900 & $890-960 \mathrm{MHz}$ \\
\hline CDMA450 & $1.92-2.17 \mathrm{GHz}$ \\
\hline JCDMA & $411-493 \mathrm{MHz}$ \\
\hline KPCS & $832-925 \mathrm{MHz}$ \\
\hline Global Position System (GPS) & $1.75-1.87 \mathrm{GHz}$ \\
\hline Lower and upper bands of WiMAX & $1574.4-1576.4 \mathrm{MHz}$ \\
\hline Lower band of WiFi & $2.3-2.4 \mathrm{GHz}$ and $2.496-2.690 \mathrm{GHz}$ \\
\hline Bluetooth & $2.412-2.4835 \mathrm{GHz}$ \\
\hline
\end{tabular}

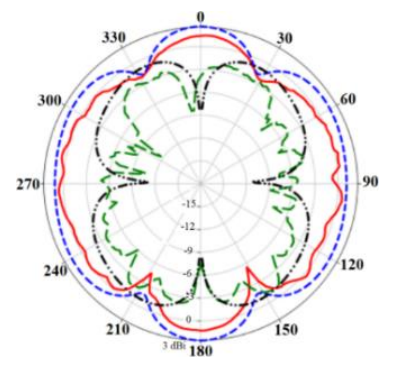

(a)

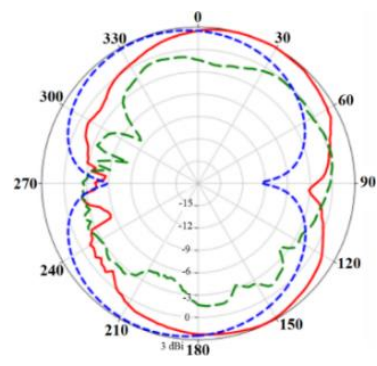

(b)

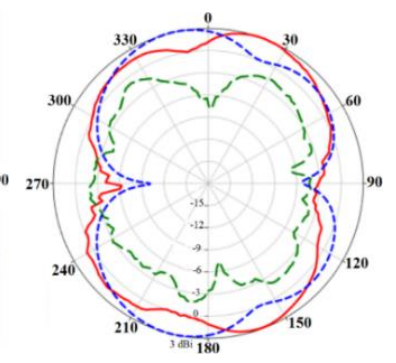

(c)

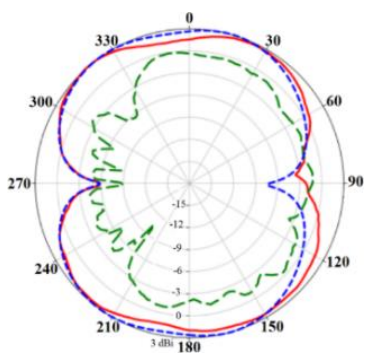

(d)

Fig. 12. Measured radiation patterns of the Antenna\#3, a) at $f: 220 \mathrm{MHz}$, b) at $f r 1: 550 \mathrm{MHz}$ (ML-slit\#2), c) at $f r 2: 1.0 \mathrm{GHz}$ (ML and stub), d) at fr3: $1.45 \mathrm{GHz}$ (ML-slit\#1). Blue, red, black, and green lines represent co-pol at E-plane (z-x), co-pol at H-plane (z-y), cross-pol at E-plane, and cross-pol at H-planes, respectively. 


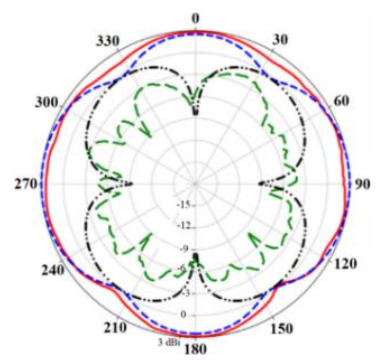

(a)

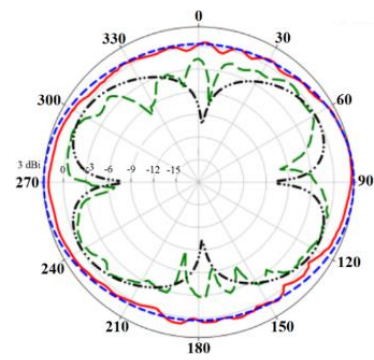

(b)

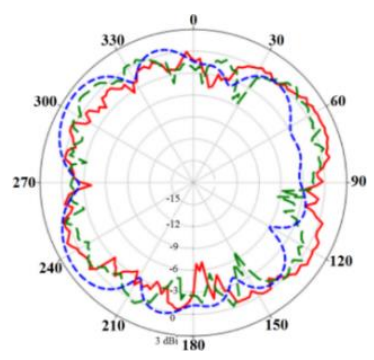

(c)

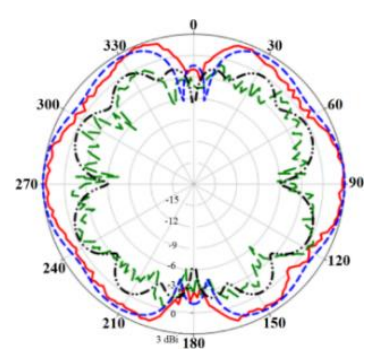

(d)

Fig. 13. Measured radiation patterns of the Antenna\#3, a) at $f r 4: 1.85 \mathrm{GHz}$ (SRR\#1), b) at $f r 5: 2.15 \mathrm{GHz}$ (SRR\#2), c) at fr6: $2.5 \mathrm{GHz}$ (SRR\#3), d) at $f: 2.85 \mathrm{GHz}$. Blue, red, black, and green lines represent co-pol at E-plane $(z-x)$, co-pol at H-plane $(z-y)$, cross-pol at E-plane, and cross-pol at Hplanes, respectively.

\section{A) Effect of Symmetrically located Ground-Plane Split- Ring Resonators}

The antenna was analyzed with four symmetrically located ground-plane split-ring resonators (SRR) shown in Fig. 14. Reflection coefficient response of this antenna, in Fig. 15, shows the creation of an additional region of well matched impedance. As a result, there is improvement in the impedance bandwidth and matching. Simulated and measured fractional bandwidths are $188 \%$ and $180.32 \%$, respectively.

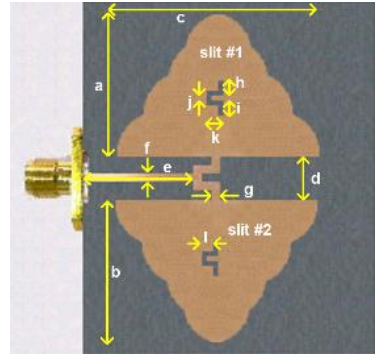

(a)

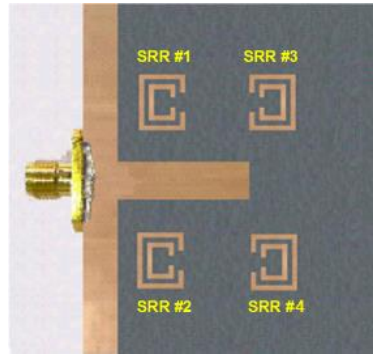

(b)
Fig. 14 Finalized antenna with symmetrically loaded ground-plane SRRs, a) front view, b) back view.

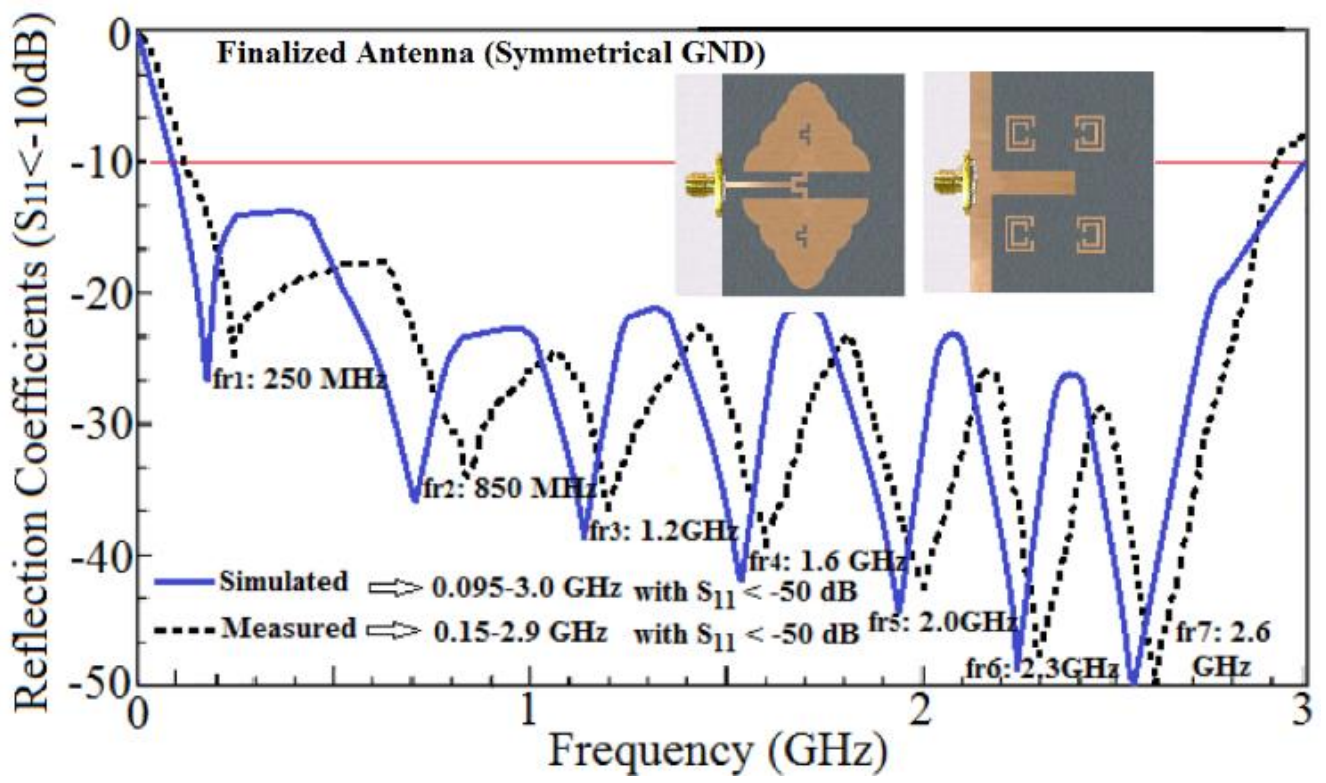

Fig. 15. Reflection coefficient response of the final antenna with four symmetrically located ground plane SRR. 


\section{COMPARISON OF THE PROPOSED ANTENNA}

Comparison of the salient characteristics (i.e. freq. range, bandwidth, gain, radiation efficiency, and size) of the proposed antenna structure with other recently reported microstrip planar antennas is given in Table 11. The proposed antenna exhibits a wide frequency range extending from $115 \mathrm{MHz}$ to $2.90 \mathrm{GHz}$ and therefore a large bandwidth performance with a relatively small foot print. Although its radiation efficiency is comparable with other antennas however its gain is relatively low.

Table 11. Comparison of the proposed antenna with the previous designs in the cited references for the freq. range, bandwidth, gain, radiation efficiency, and size.

\begin{tabular}{|c|c|c|c|c|}
\hline References & Size $\left(\mathbf{m m}^{3}\right)$ & Freq. Range / [BW] (GHz) & Max. Gain (dBi) & Max. Efficiency (\%) \\
\hline [3] & $100 \times 50 \times 9$ & $\begin{array}{l}\text { Lower band: } 0.88-0.91[0.03] \\
\text { Upper band: } 2.90-5.35[2.45]\end{array}$ & $\begin{array}{l}\text { Lower band: } 1.8 \\
\text { Upper band: } 7\end{array}$ & $\begin{array}{l}\text { Lower band: - } \\
\text { Upper band: - }\end{array}$ \\
\hline [4] & $13 \times 24 \times 1.6$ & $3.10-4.50[1.40]$ & 6.0 & 50 \\
\hline [5] & $60 \times 80 \times 0.8$ & $0.60-3.00$ (several narrow bands) & 4.0 & 95 \\
\hline [6] & $35 \times 26 \times 1.6$ & $0.88-5.90$ (several narrow bands) & 5.27 & 81.3 \\
\hline [7] & $80 \times 101 \times 1.5$ & $2.24-2.66[0.42]$ & 5.2 & 95 \\
\hline [10] & $56 \times 50 \times 1$ & $2.36-2.49[0.13]$ & - & 80.8 \\
\hline [14] & $51 \times 28 \times 1.524$ & $\begin{array}{c}\text { Low band: } 0.432-0.434[0.002] \\
\text { High band: } 2.38-2.50[0.12]\end{array}$ & $\begin{array}{l}\text { Low band: } 11.5 \\
\text { High band: } 0.5\end{array}$ & $\begin{array}{c}\text { Low band: } 7 \\
\text { High band: } 72\end{array}$ \\
\hline [21] & $50 \times 50 \times 3.81$ & $2.72-3.17[0.45]$ & 7.0 & - \\
\hline [23] & $100 \times 100 \times 9.6$ & $1.50-2.60[1.10]$ & 6.4 & - \\
\hline [24] & $47.59 \times 31.86 \times 8.27$ & $1.00-1.30[0.30]$ & 6.0 & - \\
\hline [25] & $70 \times 42 \times 28$ & $0.75-1.00[0.25]$ & 8.0 & - \\
\hline [25] & $45 \times 70 \times 10$ & $2.10-3.00[0.90]$ & 9.5 & - \\
\hline$[26]$ & $145 \times 127 \times 1.59$ & $0.78-0.94[0.16]$ & 12.5 & - \\
\hline This paper & $48.32 \times 43.72 \times 0.8$ & $0.115-2.90[2.785]$ & 2.35 & 78.85 \\
\hline
\end{tabular}

\section{CONCLUSION}

Feasibility of a novel printed monopole antenna is demonstrated for wideband applications. The antenna is composed of back-to-back tree-shaped radiating patches on which is etched a meandered line slot and the groundplane is loaded with four double split-ring resonators. The grounded-plane is a truncated T-shaped structure. These modifications to the antenna introduce additional regions of well matched impedance that enhance the antennas impedance bandwidth. The antenna exhibits a fractional bandwidth of $185 \%$ from $115 \mathrm{MHz}-2.90 \mathrm{GHz}$ for $\left|S_{11}\right| \leqq-10 \mathrm{~dB}$ with a peak gain of $2.35 \mathrm{dBi}$ and radiation efficiency of $78.8 \%$ at $1.45 \mathrm{GHz}$. The antenna has dimensions of $48.32 \times 43.72 \times 0.8 \mathrm{~mm}^{3}$ that is equivalent to $0.235 \lambda_{0} \times 0.211 \lambda_{0} \times 0.003 \lambda_{0}$, where $\lambda_{0}$ is free-space wavelength at the resonance frequency of 1.45 GHz. The antenna radiates approximately omnidirectionally. The measured and simulated results are in good agreement. Owing to the compact size, simple design and easy integration with RF front-end circuitry, the proposed antenna is attractive for use in wireless communication systems.

\section{REFERENCES}

[1] C.A. Balanis, Antenna Theory: Analysis and Design. New York, NY, USA: Wiley, 2005.

[2] A. Ramachandran, S. Mathew, V. Rajan, V. Kesavath, "A compact triband quad-element MIMO antenna using SRR ring for high isolation," IEEE Antennas \& Wireless Propagation Letters, vol. 16, 2017, pp. 1409 - 1412.

[3] W. An, Z. Shen, J. Wang, "Compact low-profile dual-band tag antenna for indoor positioning systems," IEEE Ant. \& Wirel. Propag. Lett., vol. 16, 2017, pp. 400 - 403.

[4] S. Yadav, A.K. Gautam, B.K. Kanaujia, K. Rambabu, "Design of band-rejected UWB planar antenna with integrated Bluetooth band," IET Microwaves, Antennas \& Propagation, vol. 10, issue 14, 2016, pp. $1528-533$.

[5] Y. Yang, Q. Chu, C. Mao, "Multiband MIMO antenna for GSM, DCS, and LTE indoor applications," IEEE Antennas and Wireless Propagation Letters, vol. 15, 2016, pp. $1573-1576$.

[6] M. Alibakhshi-Kenari, M. Naser-Moghadasi, R.A. Sadeghzadeh, B.S. Virdee, "Hexa-band planar antenna with asymmetric fork-shaped radiators for multiband and broadband communication applications," IET Microwaves, Antennas \& Propagation, vol. 10, issue 5, 2016, pp. $471-478$.

[7] W. Li, Z. Xia, B. You, Y. Liu, Q.H. Liu, "Dual-polarized Hshaped printed slot antenna," IEEE Antennas and Wireless Propagation Letters, vol. 16, 2017, pp. $1484-1487$.

[8] K. Ding, C. Gao, T. Yu, D. Qu, "Wideband CP slot antenna with backed FSS reflector," IET Microwaves, Antennas \& Propagation, vol. 11, issue 7, 2017, pp. $1045-1050$.

[9] C. -T. Lee, S.-W. Su, S.-C. Chen, C.-S. Fu, "low-cost, directfed slot antenna built in metal cover of notebook computer for 
2.4-/5.2-/5.8-GHz WLAN Operation,” IEEE Trans. on Antennas \& Propag., vol. 65, issue 5, 2017, pp. 2677 - 2682.

[10] Y. Dong, J. Choi, T. Itoh, "Folded strip/slot antenna with extended bandwidth for WLAN application," IEEE Ant. \& Wireless Propagation Letters, vol. 16, 2017, pp. 673 - 676.

[11] A. Akbarpour, S. Chamaani, "Dual-band electrically coupled loop antenna for implant applications," IET Microwaves, Antennas \& Propagation, vol. 11, issue 7, 2017, pp. $1020-1023$.

[12] Y. Liu, F. Liu, D. Yang, J. Xu, Z. Zhang, "Type of active impulse noise suppressing method based on double-loop antennas in very low frequency/ultra-low frequency coupling communications," IET Microwaves, Antennas \& Propagation, vol. 11, issue 6, 2016, pp. $867-873$.

[13] P. Sadeghi, J. Nourinia, C. Ghobadi, "Square slot antenna with two spiral slots loaded for broadband circular polarisation," Electronics Letters, vol. 52, issue 10, 2016, pp. 787 - 788.

[14] J. L. Buckley, K.G. McCarthy, L. Loizou, B. O'Flynn, C. O'Mathuna, "a dual-ISM-band antenna of small size using a spiral structure with parasitic element," IEEE Antennas and Wireless Propagation Letters, vol. 15, 2016, pp. 630 - 633.

[15] C. Sharma, D.K. Vishwakarma, "Miniaturization of spiral antenna based on Fibonacci sequence using modified Koch curve," IEEE Antennas and Wireless Propagation Letters, vol. 16, 2017, pp. $932-935$.

[16] F. Yang and Y. Rahmat-Samii, "Reflection phase characterizations of the EBG ground plane for low profile wire antenna applications," IEEE Trans. Antennas Propag., vol. 51, no. 10, pp. 2691-2703, Oct. 2003.

[17] A. Vallecchi, J. R. de Luis, F. Capolino, and F. de Flaviis, "Low profile fully planar folded dipole antenna on a high impedance surface," IEEE Trans. Antennas Propag., vol. 60, no. 1, pp. 5162, Jan. 2012.

[18] J. M. Bell and M. F. Iskander, "A low-profile Archimedean spiral antenna using an EBG ground plane," IEEE Antennas Wireless Propag. Lett., vol. 3, no. 1, pp. 223-226, 2004.

[19] J. R. James and P. S. Hall, Handbook of Microstrip Antennas. London, U.K.: Peter Peregrinus, 1989.

[20] K.M. Luk, C.L. Mak, Y. Chow, and K.F. Lee, "Broadband microstrip patch antenna," Electron. Lett., vol. 34, pp. 14421443, Jul. 1998.

[21] K.Q. da Costa, V. Dmitriev, D.C. Nascimento, and J.C. da S. Lacava, "Broadband L-probe fed patch antenna combined with passive loop elements," IEEE Antennas Wireless Propag. Lett., vol. 6, pp. 100-102, 2007.

[22] V. G. Kasabegoudar and K.J. Vinoy, "Coplanar capacitively coupled probe fed microstrip antennas for wideband applications," IEEE Trans. Antennas Propag., vol. 58, no. 10, pp. 3131-3138, Oct. 2010.

[23] K.L. Wong and H.C. Tung, "An inverted U-shaped patch antenna for compact operation," IEEE Trans. Antennas Propag., vol. 51, no. 7, pp. 1647-1648, Jul. 2003.

[24] F. Namin, T. G. Spence, D. H. Werner, and E. Semouchkina, "Broadband, miniaturized stacked-patch antennas for L-band operation based on magneto-dielectric substrates," IEEE Trans. Antennas Propag., vol. 58, no. 9, pp. 2817-2822, Sep. 2010.

[25] R. Chair, C. L. Mak, K. F. Lee, K. M. Luk, and A. A. Kishk, "Miniature wide-band half U-slot and half E-shaped patch antennas," IEEE Trans. Antennas Propag., vol. 53, no. 8, pp. 2645-2652, Aug. 2005.

[26] Y. Chen, S. Yang, and Z. Nie, "Bandwidth enhancement method for low profile E-shaped microstrip patch antennas," IEEE Trans. Antennas Propag., vol. 58, no. 7, pp. 2442-2447, Jul. 2010 .

[27] J. Helszajn and D. S. James, "'Planar Triangular Resonators with Magnetic Walls,', IEEE Trans. Microwave Theory Tech., Vol. MTT-26, No. 2, 1978, pp. 95-100. 